\title{
Necrópolis chilotas: un caso en la diversidad patrimonial de un territorio insular
}

Antonio Sahady Villanueva, Felipe Eduardo Gallardo Gastelo

José Bravo Sánchez

\section{Filiación}

Antonio Sahady V. et al., son I nvestigadores en el Instituto de Restauración Arquitectónica (INREAR) de la Facultad de Arquitectura y Urbanismo de la Universidad de Chile. Santiago de Chile.

Email:asahady@uchile.cl

\section{Resumen}

Chiloé, en su condición de ínsula, se expresa en una riqueza cultural fuertemente territorializada, capaz de defenderse de las invasivas influencias foráneas. Merece la pena destacar una de las vigas que sostiene su andamiaje cultural: el poder omnipresente de la religión. En este sentido, sobresalen los cementerios chilotes como un ejemplo claro de simbiosis cultural religiosa que se manifiesta en una arquitectura mortuoria singular que enriquece al espacio y paisaje religioso de cada localidad.

\begin{abstract}
Chiloé, in its condition of island, it's express in a cultural wealth, heavily territorialized, with a capacity of defense of the invaders foreign influences. It's worth while to highlight at one of the girders that supports its cultural scaffolding: the omnipresent power of the religion. In this sense, chilotes cemeteries project like a clearly example of cultural symbiosis that it's exposes in a singular mortuary architecture that riches at religious space and landscape of each settlement.
\end{abstract}

\section{I ntroducción}

Los cementerios en Chiloé se han enriquecido desde sus inicios de los elementos patrimoniales presentes en la Cultura Chilota. Ellos han permitido ser un registro material e inmaterial de un pueblo insular y "bordemarino"1, cuya vida ha transcurrido por los vaivenes de las mareas. Por esto, es que muchos autores como Plath, Cárdenas, León, entre otros, los han destacado en sus trabajos e investigaciones como elementos sociales, económicos, tradicionales y mitológicos del pueblo chilote.

A lo anterior, se suma la investigación del INREAR a los camposantos chilotes a través del análisis de casos de estudio a diversos asentamientos, en el cual, no sólo se describe su arquitectura sino también el lugar que poseen, al enfatizarlos en el espacio vital del poblado donde se emplazan.

Sin embargo, debido a la vorágine que ha traído la globalización al archipiélago, los cementerios en algunos de los poblados corren el riesgo de caer en el olvido debido al descuido de sus habitantes.

\footnotetext{
${ }^{1}$ Expresión en uso en Chiloé, por costanero.
} 


\section{Evolución histórica de los camposantos en Chiloé}

La historia de los cementerios chilotes se remonta a tres períodos: prehispánico, hispano y republicano.

En el período prehispánico, el concepto de cementerio dista mucho para los aborígenes de esta zona del que se conoce hoy. Ha resultado muy difícil identificar, hasta el momento, el lugar que los chonos ${ }^{2}$ escogían para el entierro de sus difuntos.

Uno de los pocos relatos que habla de estos lugares sagrados pertenece a John Byron, autor del siglo XVIII. Afirma que los restos mortuorios encontrados se encontraban en posición fetal, con las rodillas flexionadas hacia los hombros. Este aserto se contradice con la recreación de una tumba chono expuesta en el Museo Regional de Castro, que revela un desarrollado culto mortuorio, propio de un pueblo canoero: se representa un cuerpo yacente, cubierto por cortezas de madera nativa, en una postura de adoración. La caja que lo cuna - una suerte de ataúd chono- manifiesta una diferencia entre el tronco y la cabeza del cadáver. Para los veliches, en cambio, los difuntos eran enterrados en un ataúd que no era otra cosa que un tronco labrado en forma de canoa; dependiendo del linaje de la familia del fallecido, este terminaba sepultado en una loma o en una ramazón, aunque en algunos casos el féretro era dejado en el suelo para cubrirlo con un montículo de tierra y rocas, (ver Figs.la y 1b).

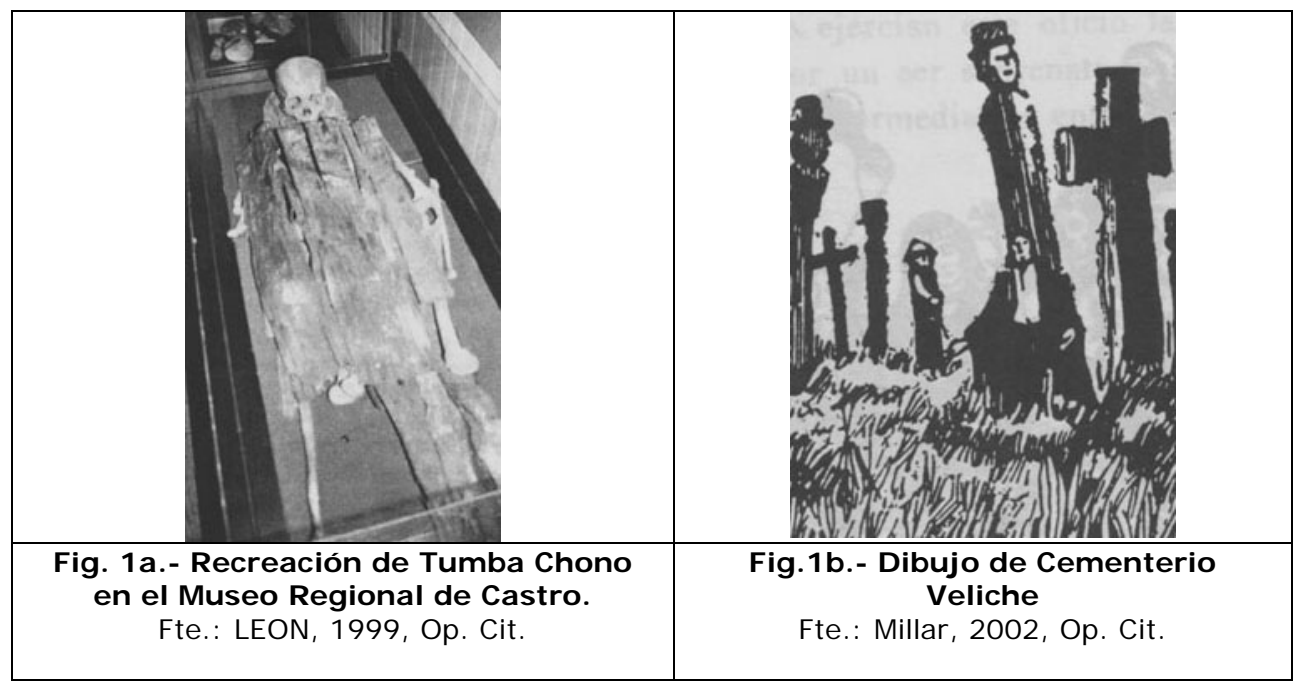

En el caso de los urnas cavadas, eran emplazadas en disposición vertical en un árbol; en otras ocasiones, descansaban en gruesos puntales. Asociadas a las tumbas veliches, algunas veces se les rodeaba por un cerco de tablas y se les agregaba algún poste de madera con un tosco tallado antropomorfo. Las crónicas del siglo XVIII dan cuenta de casos de hombres destacados por el pueblo, en cuyos sepulcros se colocaban caballos muertos o cueros de caballo colgando en una vara que era apoyada entre los horcones. La cremación de cadáveres sólo se realizaba cuando el lugar de entierro quedaba muy lejos del lugar de origen del extinto.

Durante el dominio español, el lugar de enterramiento de los muertos era en el interior de la iglesia más próxima, al menos para los privilegiados. En razón de la jerarquía del personaje, se inhumaba más cerca del altar mayor o de la puerta de entrada del

\footnotetext{
${ }^{2}$ Indio del archipiélago chilote, fundamentalmente navegante.
} 
templo. Entre 1976 y 1983, cuando se repuso el entablado del templo de Achao, aparecieron muchos cajones mortuorios.

Con la anexión de Chiloé a la República, la Iglesia prohibió el enterramiento en intramuros y el Estado legisló respecto de los cementerios. Pero los cementerios de campo, en general, quedaron anejos a la iglesia, de modo que fueran dotados por la comunidad con la misma sacralidad que se le confiere al templo mismo.

La construcción de cementerios en Chiloé comenzó en 1836. Quince años después debían reunir las siguientes condiciones:

....los panteones de las iglesias parroquiales como los que hubiere en las capillas o pueblos pequeños de distrito parroquial, tengan suficiente capacidad; y que el cercado que cierra el recinto sea de poste o madrinas bien unidas y de proporcionadas alturas; y que se coloque en medio del panteón una cruz de cuatro o cinco varas, sobre una peña de piedras, y la puerta de él sea segura y se mantenga cerrada, guardando el párroco la llave, y en otros pueblos del territorio parroquial, la persona de confianza a quien hiciere este cargo" ${ }^{3}$.

Lo anterior demuestra que los cementerios quedaron, desde los inicios, bajo la protección eclesiástica.

“Estas verdaderas ciudades de los muertos se caracterizan en un comienzo por la construcción de lápidas, cruces y tumbas (en algunos casos en forma de casa) hechas principalmente de madera, incluso muchos de sus adornos florales que los embellecen son fabricados de papel, puesto que tienen la capacidad de resistir el mal tiempo". ${ }^{4}$

El texto es elocuente: la cultura de la muerte ya tenía un notable desarrollo a mediados del siglo XIX y es una de las vigas maestras de su identidad.

\section{Características arquitectónicas de los sacramentales ${ }^{5}$ chilotes}

Los cementerios chilotes se han caracterizado por mostrar la peculiar forma en que este pueblo costanero ha entendido la muerte, construyendo sus tumbas con ornamentos típicos de la cultura de la madera y campesina, tan propia de esta comarca encantada. Ejemplo de ello son las sepulturas en forma de casa, los altares de concreto, las cruces talladas en madera o el mausoleo con fotos recordatorias.

Asimismo, los sacramentales chilotes permiten dar cuenta de la historia social y personal de los habitantes, o de los rituales y supersticiones que giran en torno al espacio sagrado chilote, (ver Fig. 2).

\footnotetext{
${ }^{3}$ RETAMAL, citado por LEÓN. La muerte de la cultura en Chiloé. Ed. Dibam. Santiago. Chile. 1998

${ }^{4}$ LEÓN. Op. Cit., 1998.

${ }^{5}$ En Madrid, [y en Chiloé], cementerio utilizado por una cofradía sacramental. Fte: Diccionario de la Lengua Española, Real Academia Española, 2008.
} 


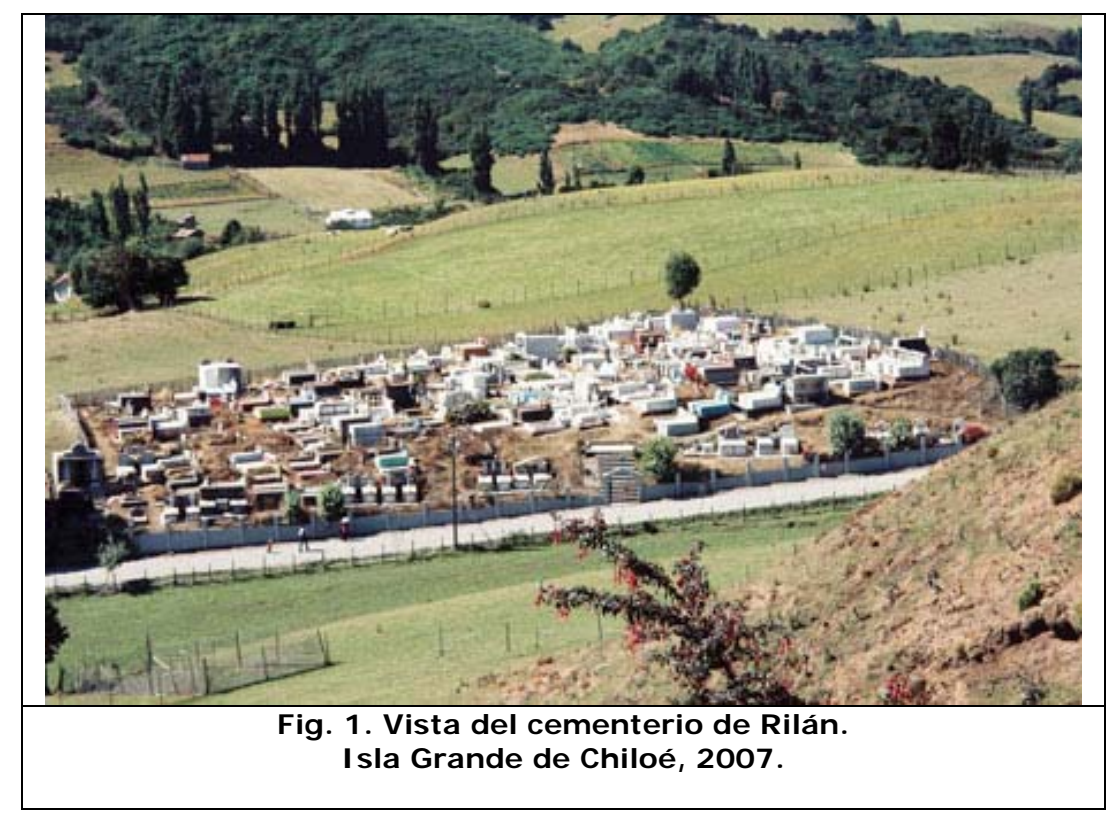

Desde el punto de vista arquitectónico, una de las singularidades de las construcciones fúnebres que destacan en las necrópolis es la "casa-tumba". Como lo dice su nombre, se trata de una vivienda pequeña, construida originalmente de madera y revestida con tejuelas, aunque las hay también de fierro galvanizado y hormigón. La idea que fundamenta este tipo de construcción es la recreación del hogar del difunto en su aspecto exterior. Para mantener vivo su recuerdo se suele construir un altar, en el interior, señalando el lugar donde yace. Allí se hinca una cruz, con su nombre inciso además de las fechas de nacimiento y muerte- y, como elementos secundarios, algunas bancas dispuestas lateralmente para que descansen los deudos. La "casatumba" recrea el ambiente de cobijo interior, apropiado para guarecerse cuando el clima es hostil e invita a los encuentros frecuentes, otorgando a la muerte un sentido más familiar, cercano y aceptable, (ver Figs. $3 a$ y $3 b$ ). 


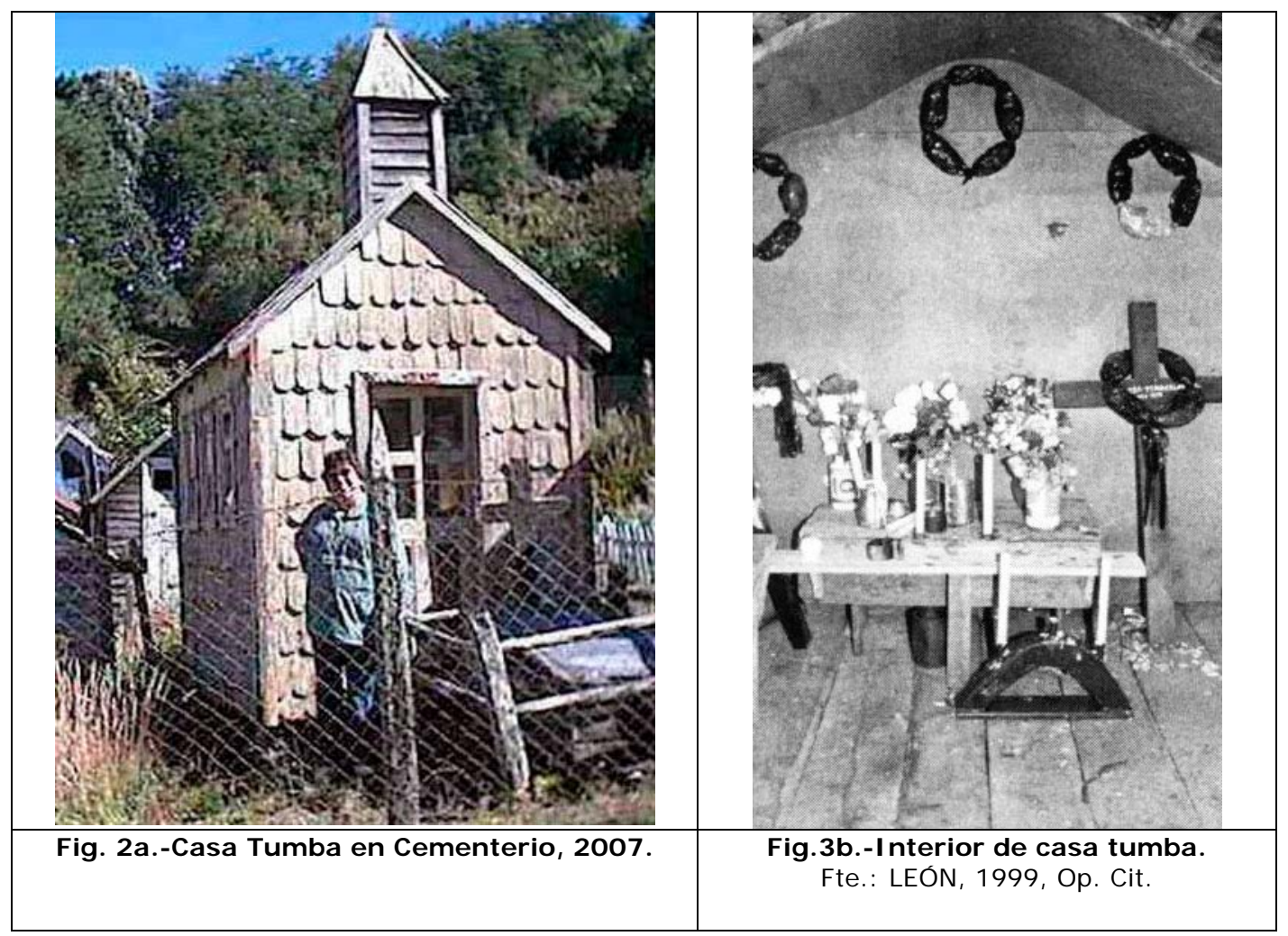

Entre los llamativos objetos que conforman la sagrada panoplia funeraria están las cruces de madera que emergen desde las tumbas de tierra. Al predominio del azul y del blanco se agrega la presencia de alguna corona de flores artificiales, confirmando la influencia indígena en este tipo de enterramiento. No son extrañas, tampoco, las tumbas de madera que se encuentran protegidas por un "corral" o cerco, (ver Fig. 4).

La paleta cromática que presentan las tumbas chilotas es variada e intensa, sin atenuantes. Destacan los colores violeta, rosado, azul, verde y amarillo. El color blanco y el celeste se destinan, habitualmente, a identificar las tumbas de niños o "angelitos". La muerte, para el chilote, no está asociada con la oscuridad del negro. Por el contrario: los cementerios son un lugar de encuentro más, un centro de comunión entre vivos y muertos. Eso explica su luminosidad, su imagen colorida, su conexión directa con la realidad cotidiana. 


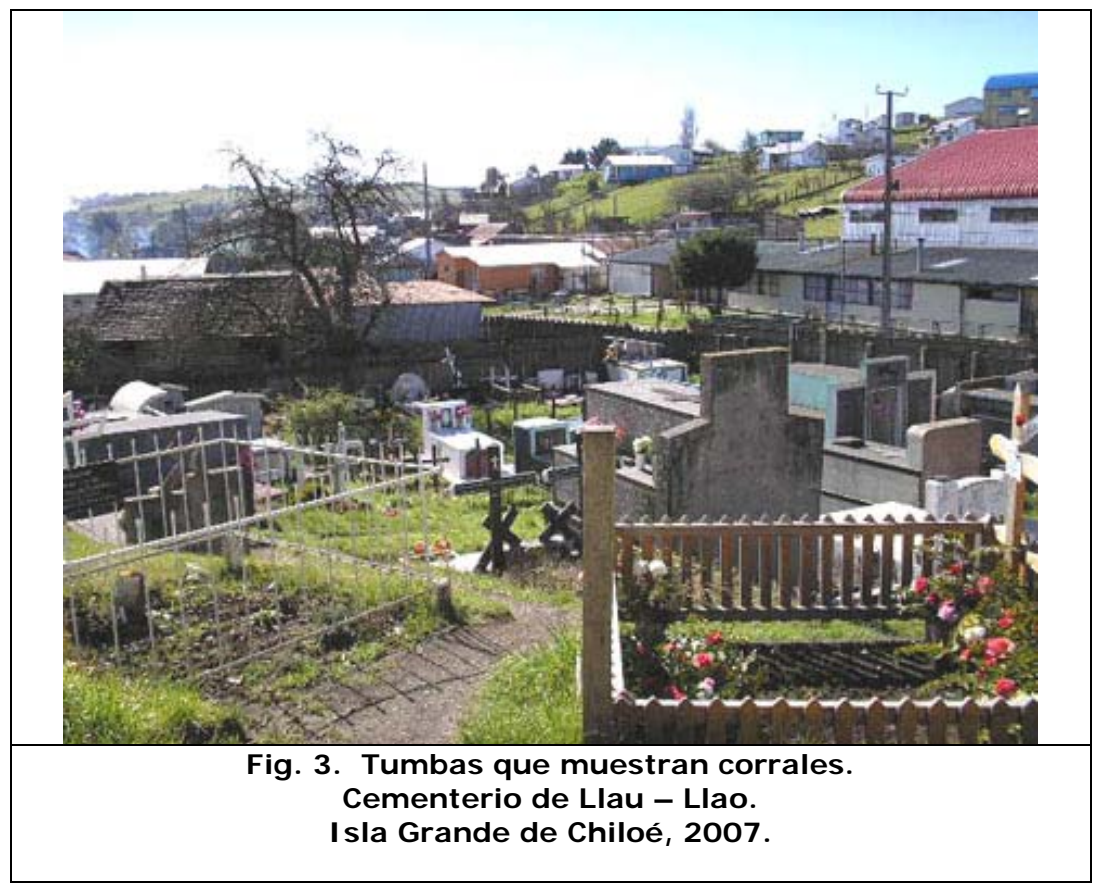

Es curiosa la disposición de las tumbas en los cementerios chilotes: de preferencia, la cabeza de los difuntos se orienta hacia el oriente o hacia el sur, siguiendo la tradición indígena, para quienes la localización de las lápidas tenía relación con las regiones celestiales donde habitan los espíritus benignos que protegen a los fallecidos. En los poblados "bordemarinos", los sepulcros, por lo general, miran hacia el mar.

Otra característica propia de los sepulcros chilotes es la presencia de los retratos y "la hora fatal". Se trata de una fotografía del extinto, junto a la que aparece la fecha y hora del deceso, a modo de registro. La naturalidad con que se expone un hecho tan doloroso como la muerte, da cuenta del sentido que este trance tiene para el chilote: un paso más en el proceso de la vida, (ver Figs. $5 a$ y $5 b$ ). 


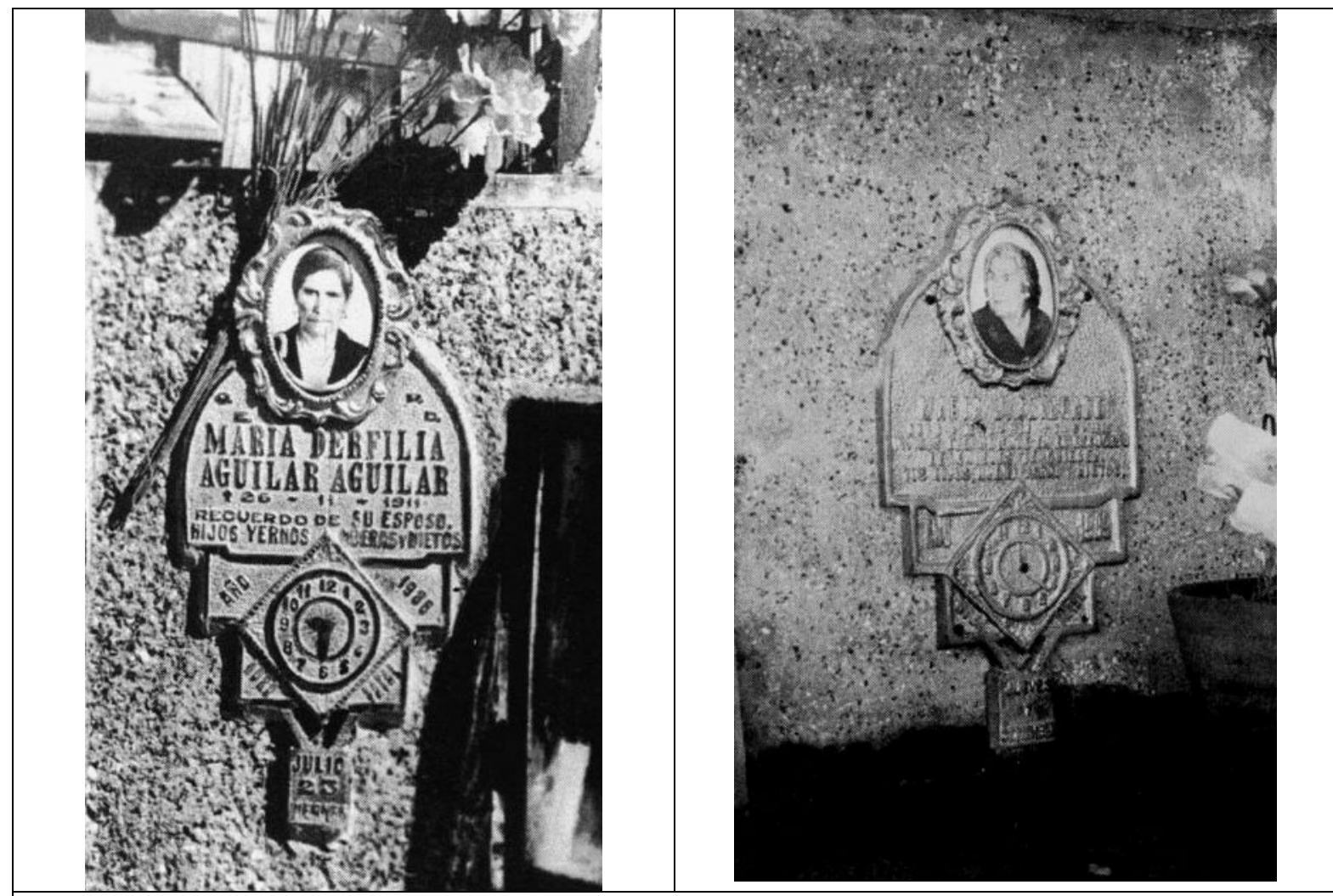

Figs. 4 a y 5 b.- Ejemplos de retrato y "Hora Fatal" presente en muchas tumbas de los cementerios Chilotes.

Fte.: LEÓN, 1999, Op. Cit.

Lastimosamente, algunos camposantos chilotes se encuentran en el más absoluto abandono. Algunas veces las causas son naturales: movimientos de tierra, cambios de mareas que inundan los territorios sagrados. Pero, con más frecuencia, la responsabilidad recae en los deudos y en la comunidad, que en la actualidad pecan de desidia y menosprecio por una cultura de hondas raíces. El tiempo de la globalización arrasa con las tradiciones, con las costumbres vernáculas, con las religiones autóctonas. En este caso se olvida a los muertos, que siempre fueron parte de la comunidad viva, (ver Fig. 6).

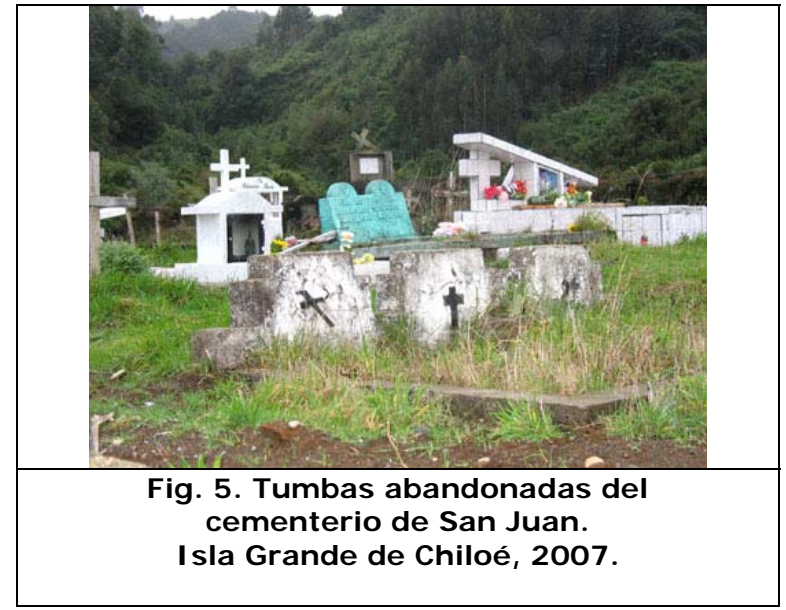




\section{Características culturales}

Para los campesinos chilotes, el respeto al camposanto ha sido sagrado; cualquier actividad ajena a su espíritu puede entenderse como profanación. Tampoco se justifica retirar algo de allí: ni flores, ni madera, ni tierra. Cualquier despojo se entenderá como un mal presagio.

En general, el imaginario mítico de Chiloé es un panteón de esperpentos y criaturas monstruosas asociadas más a la muerte que a la vida. Sin embargo, en el interior de esa dimensión, se establece cierto resguardo y equilibrio de la naturaleza a través de la muerte, el temor y al castigo.

Muchas son las supersticiones asociadas al modo de vida del campesino chilote con sus camposantos. Autores, como Cavada, Plath y Cárdenas, a través de la refranería popular han logrado dejar constancia de ellas:

- "No sirve dejar estos gualatos con tierra de cementerio. Dicen que las siembras no producen."

- "Tampoco hay que sembrar después de haber asistido a un funeral; ni siquiera se puede atravesar una siembra después de haber estado en un cementerio o funeral."

- "Es que la tierra de cementerio es muy dañina. Hay gente envidiosa que tira esta tierra por las cuatro esquinas de la siembra de un contrario para arruinarla."

- "Hay que plantar un arbolito en la sepultura para saber el destino del difunto. Si enverdece va a la Gloria Eterna, si se seca está en las flamas del infierno."

Aunque el territorio de la muerte está aislado de los vivos, se conecta en fechas rituales. Así, el día $1^{\circ}$ de noviembre (o el día de la fiesta patronal), el cementerio cobra vida, sobre todo en aquellos casos en que es el punto final de la procesión del santo de la devoción popular y un lugar de encuentro de los familiares con sus fallecidos. En cierto modo, estas pequeñas ciudadelas recrean el imaginario de la sociedad local, (ver Fig. 7).

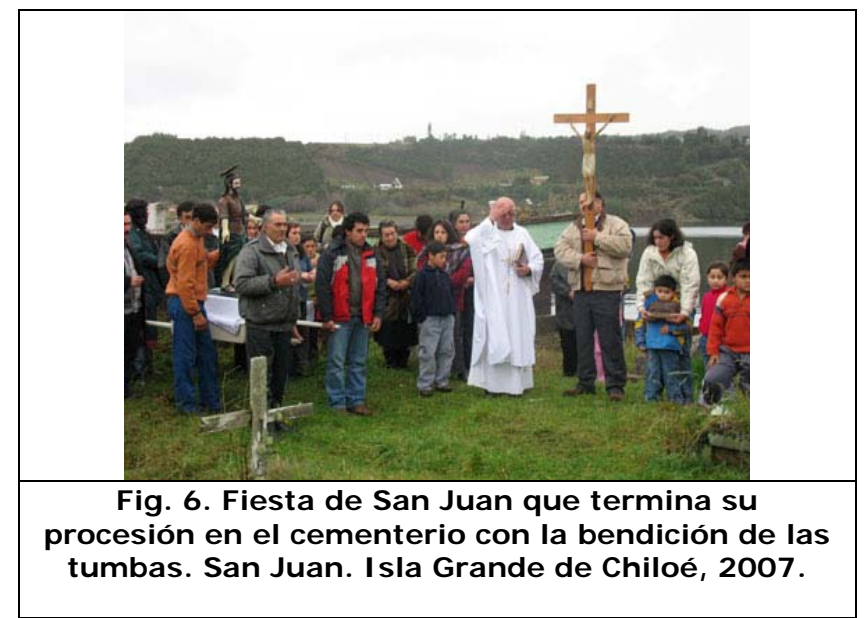




\section{Estudio casos de cementerios chilotes realizado por I NREAR}

Entre los años 2005 y 2007 el Instituto de Restauración Arquitectónica de la Facultad de Arquitectura y Urbanismo de la Universidad de Chile ha trabajado en torno al espacio religioso de Chiloé, constituido por cuatro elementos fundamentales: la iglesia, la explanada jesuítica o plaza cívica, el cementerio y el muelle. Para ello se basó en un modelo concéntrico, cuyo centro es el templo y, adyacente a él, los otros elementos que componen el espacio sagrado chilote.

En relación con el cementerio se estudiaron sus características en función de su emplazamiento (distancia hasta el templo) y del tipo de entidad poblada al que pertenecía. Para ello se tomaron cuatro casos tipo: el caserío rural de Caguach, la aldea rural de Llau - Llao, el pueblo de Achao y la Ciudad de Castro, (ver Fig. 8).

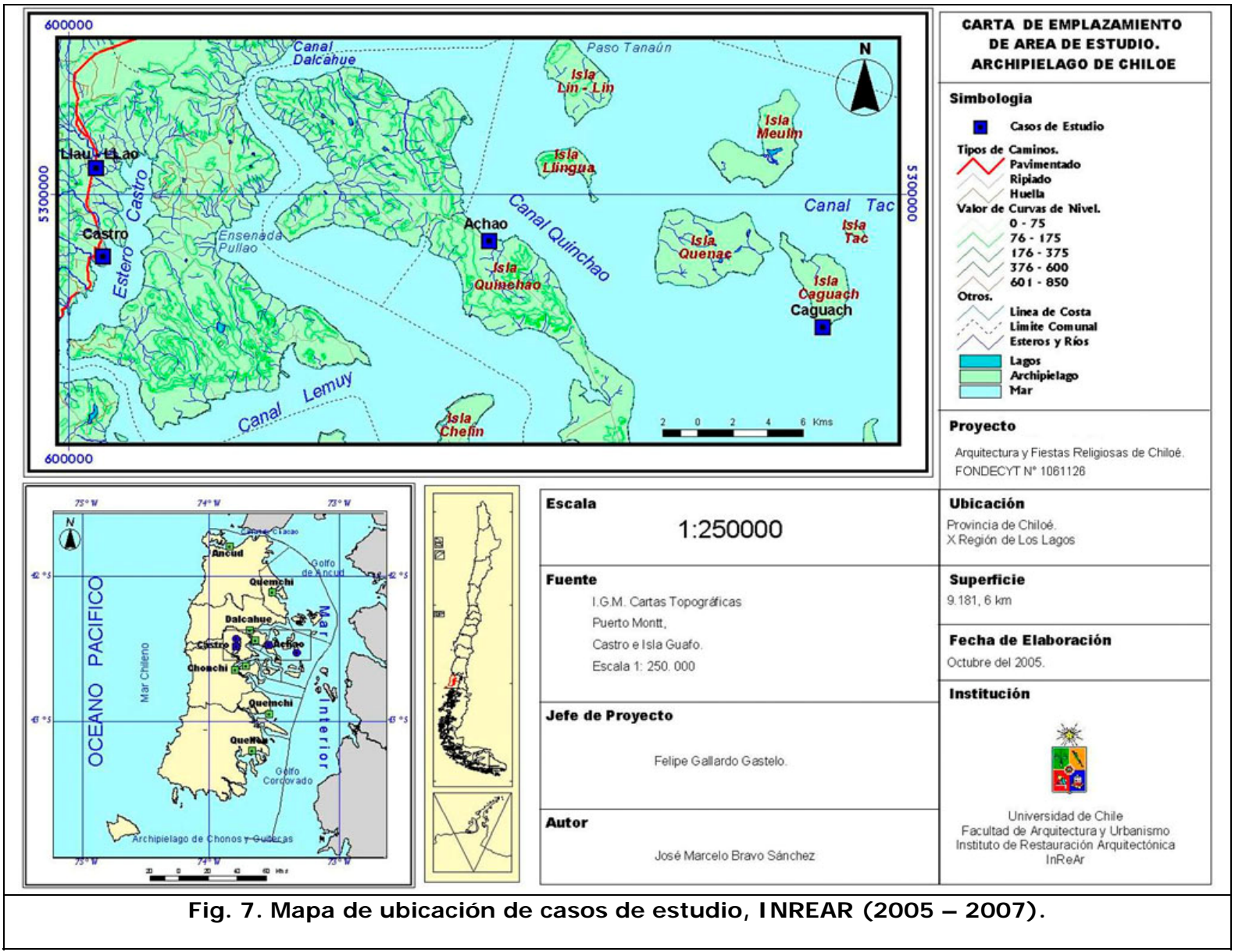

Cada caso es diferente y enseña el grado de gravitación que el cementerio tiene en esta constelación de elementos que conforman el espacio religioso:

EL CEMENTERIO DE CAGUACH, emplazado en un sector colindante con la explanada, se une a ella a través de un pequeño callejón; su superficie es de $3.590,47 \mathrm{~m}^{2}(51,41$ $\mathrm{m}$. de ancho y 69,84 $\mathrm{m}$. de largo). El camposanto caguachano se caracteriza por ser sencillo y rústico y por tener dos accesos. En el espacio de la necrópolis se han dispuesto las tumbas de forma aleatoria, sin orden alguno; existen más tumbas en 
tierra que nichos y mausoleos. En ellas se aprecian mayoritariamente cruces de madera y hierro, no así lápidas, (ver Figs. 9 a y 9 b).

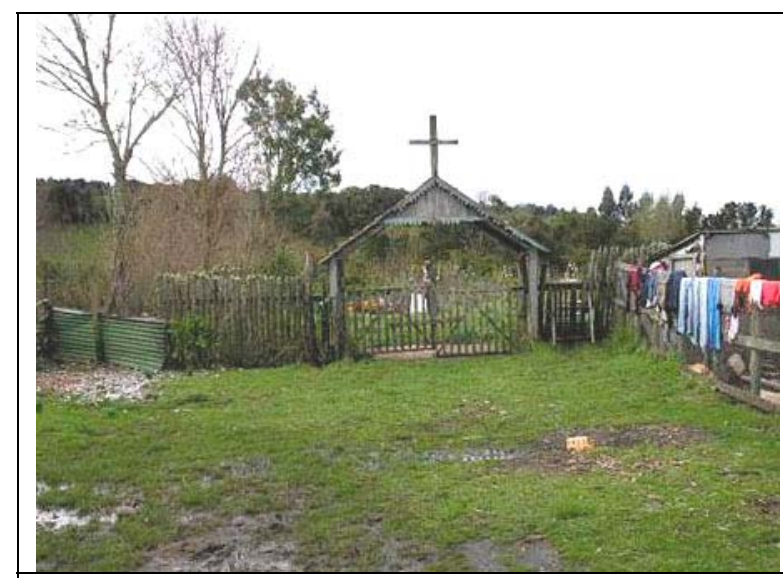

Fig. 8 a.- Entrada al cementerio de Caguach,

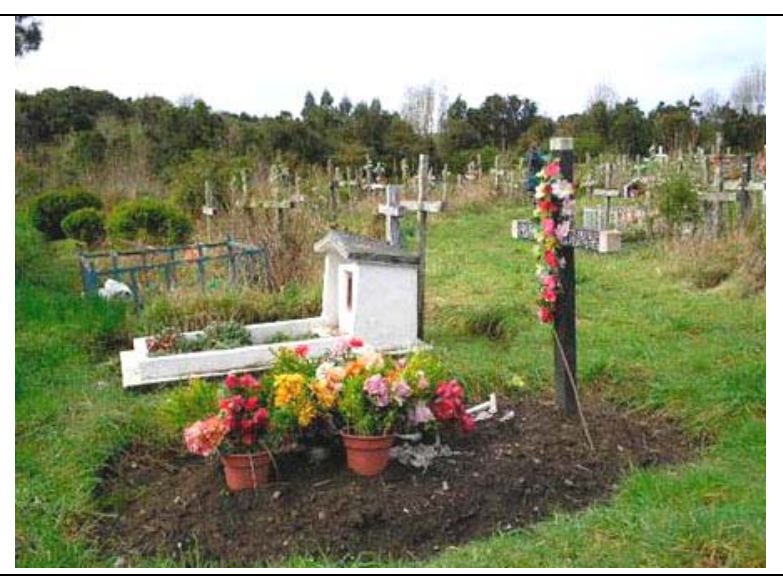

Fig. 9 b.- I nterior del cementerio de Caguach, 2007.

EL CEMENTERIO DE LLAU LLAO, colinda con la parte posterior del templo y un sector de viviendas particulares. Este rectángulo de 50,44 metros de ancho por 75,66 metros de largo $\left(3.816,29 \mathrm{~m}^{2}\right.$ está cerrado por una reja de madera que cuenta con dos entradas, con sendas cruces en sus arcos de ingreso: la principal ofrece su cara hacia la parte posterior del templo; la otra, hacia la calle Serrano, desde la parte baja del cementerio. Una calle central, pavimentada, separa en dos franjas, las tumbas. En la parte alta las bóvedas y mausoleos; en su parte baja, se alternan nichos en tierra y bóvedas. Aunque cuenta con una precaria infraestructura, dispone de un pequeño espacio a la entrada, donde los deudos tienen la posibilidad de consolarse mutuamente una vez concluida la ceremonia de inhumación, (ver Figs.10 a y 10 b).

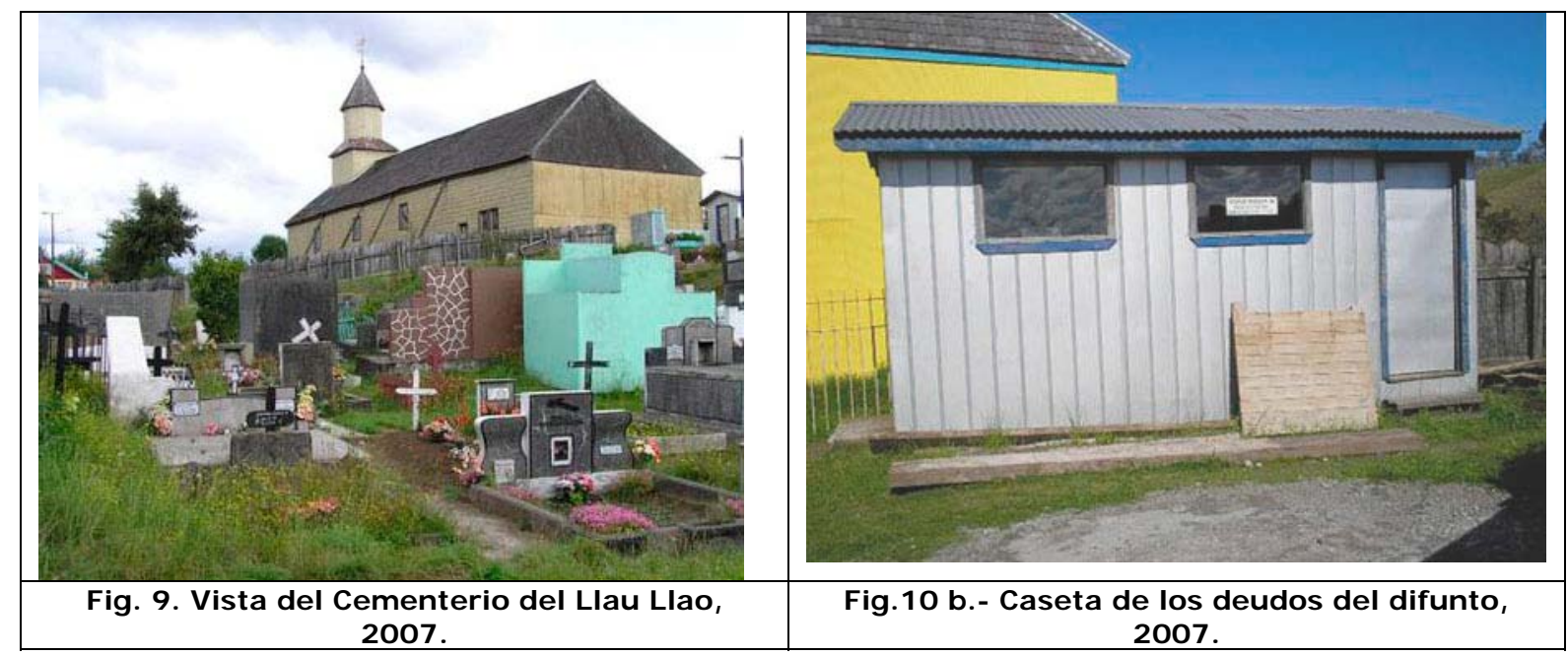

EL CEMENTERIO DE ACHAO, también de forma rectangular (172,66 metros de largo por 65,96 metros de ancho) supera, en superficie, una manzana del poblado: $11.388,65 \mathrm{~m}^{2}$. Respecto del modelo clásico del espacio religioso chilote, el camposanto se encuentra distante de la iglesia y la plaza de armas. El historiador Pedro Yánez 
afirma, sin embargo, que el antiguo cementerio estaba más cerca, en la calle Miranda. Actualmente se emplaza en el sector alto del pueblo y se caracteriza por dos zonas definidas: la primera corresponde al parroquial y la segunda, colindante con la anterior, está en el cementerio municipal. El camposanto achaíno se encuentra a 340 metros del lugar que ocupa la iglesia y se caracteriza por estar cerrado por muros de concreto con dos entradas. En él coexisten, sin orden aparente, tumbas en tierra, bóvedas y mausoleos de dos a seis cuerpos. Casi todos se enfrentan al mar, (ver Figs. 11 a y 11 b).

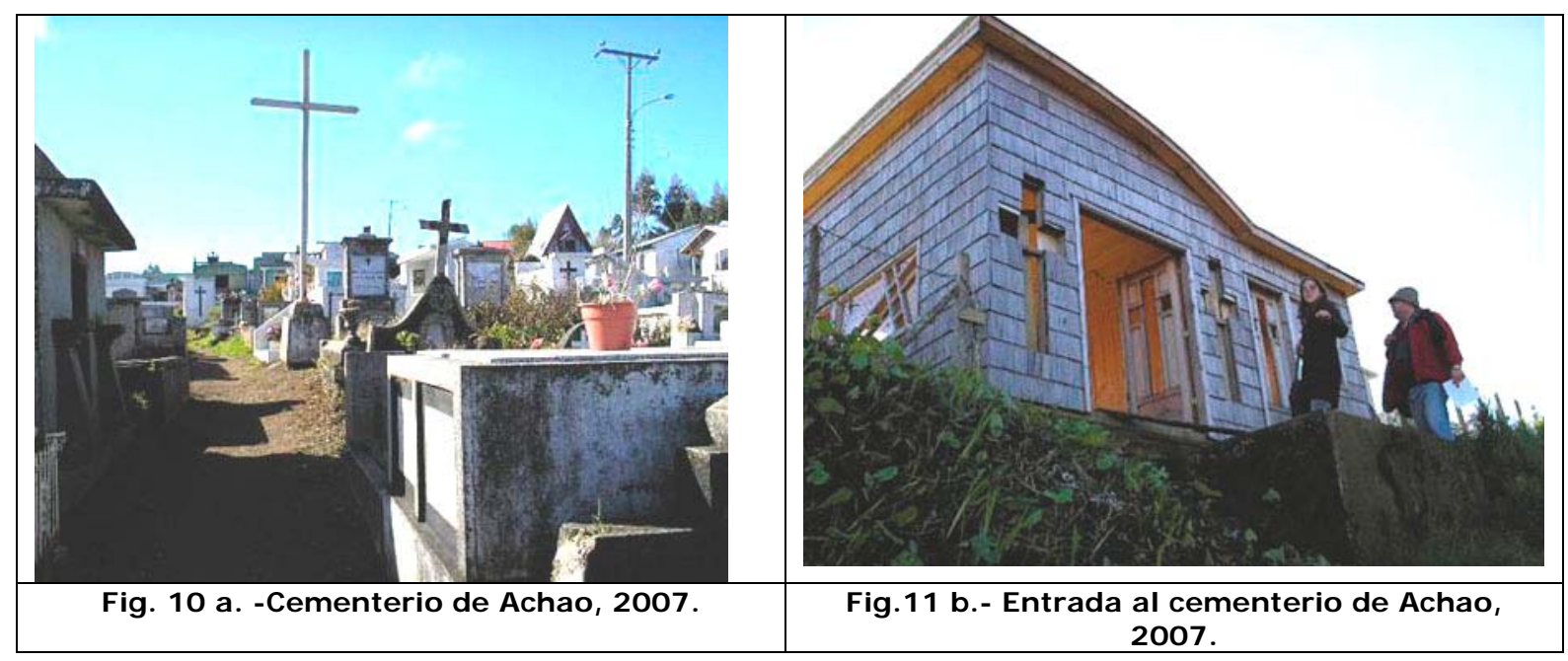

EL CEMENTERIO DE CASTRO, por su parte, es el mayor de los cuatro seleccionados, sus $35.541,56 \mathrm{~m}^{2}$ (129,01 metros de ancho por 174,6 de largo) se localizan en la calle Riffart, a 570 metros del templo de San Francisco. Sin embargo, el año 2000, cundo se realizaron excavaciones mientras se reparaba la calle San Martín - a dos metros de la fachada lateral del templo- se encontraron restos humanos que confirman que el primer cementerio estaba junto a la iglesia. (Ver Figura $\mathrm{N}^{\circ} 12$ )

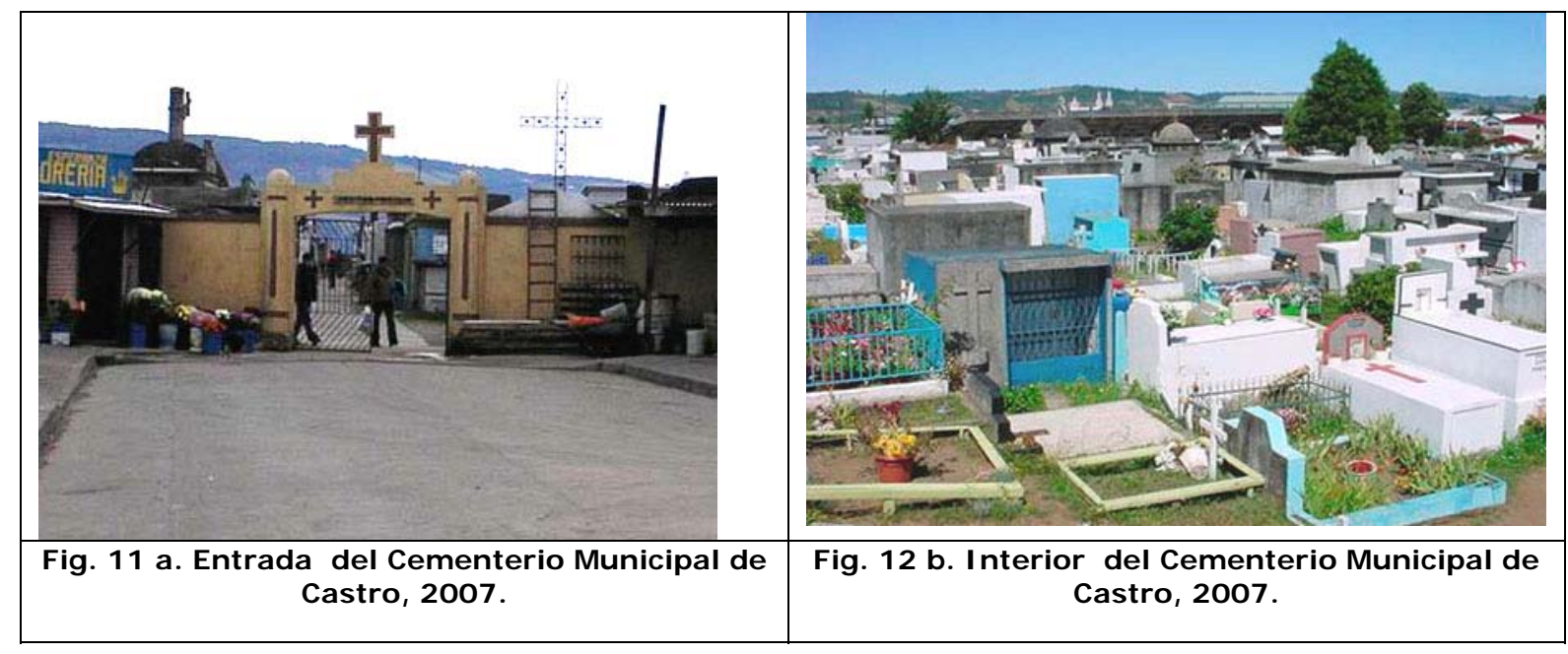


La mayor parte de las sepulturas del actual camposanto son bóvedas y mausoleos; hay, también, tumbas en tierra, dispuestas ordenadamente y definidas por senderos pavimentados que hacen posible una adecuada circulación. Dotado de los servicios básicos, este camposanto cuenta, además, con una pintoresca pérgola de flores.

A modo de complemento del antiguo cementerio municipal, en el sector alto de Castro, existe otro que está en manos de privados.

La revisión de los cuatro casos reseñados permite comprobar que, desde el punto de vista de su emplazamiento, los camposantos tienden a distanciarse del templo en relación directamente proporcional con el tamaño del asentamiento. Si en el caserío rural el templo y el cementerio conforman una unidad, en la ciudad la separación entre ambos es muy grande.

El sentimiento de propiedad de la comunidad respecto del camposanto sufre un fenómeno similar: se distancia la comunidad del cementerio en tanto el asentamiento urbano es más grande y, consiguientemente, más impersonal. A modo de compensación, es justo reconocer que la mejor dotación de servicios básicos y una administración más organizada permiten una mejor manutención de los camposantos de la ciudad consolidada.

\section{Conclusiones}

Los cementerios chilotes, entendidos como un componente del espacio religioso, que sólo tienen sentido con la presencia del usuario, sugieren algunas conclusiones:

1.-Los cementerios están insertos en la memoria colectiva del pueblo chilote debido a su valor histórico, social, económico, cultural y patrimonial, confirmando que el término "lugar religioso del descanso eterno" es más que una visión geométrica o física del espacio en que se encuentra.

2.-El espacio destinado al camposanto no sólo concentra la memoria emocional de un pueblo, sino, también, es capaz de evidenciar su evolución cultural y material, hecho que se refleja en los sepulcros y en el afecto que demuestran hacia ellos sus habitantes.

3.-El espacio religioso de Chiloé, de algún modo, ha materializado la condición de cobijo o abrigo que tiene el pueblo chilote, que se expresa en sus viviendas, en los templos y, ciertamente, en la arquitectura de sus cementerios. Así se explica que el "lugar de encuentro" se haya expresado en el ejemplo de la "casa-tumba", presente en muchos cementerios de Chiloé.

4.-El cementerio chilote, así como el espacio religioso en el cual se emplaza, ha logrado adaptarse a los cambios traídos por la globalización. Sin embargo, nunca dejará de ser un lugar de encuentro para el pueblo chilote.

5.-El modelo aplicado por la investigación que se desarrolla en el Instituto de Restauración Arquitectónica de la Facultad de Arquitectura y Urbanismo de la Universidad de Chile ha (INREAR) ha demostrado que las necrópolis chilotas no son estáticas ni en el tiempo ni en el espacio $\mathrm{y}$, por ello, se reduce sólo a expresiones culturales que se asemejen a la cultura chilota. 
6.-Por último, sería aconsejable que las políticas culturales tomaran en cuenta a estos lugares a fin de integrarlos a la planificación territorial, incorporando sus múltiples valores y sus elementos culturales. Como en pocos casos, aquí se produce una auténtica fusión entre el patrimonio tangible y el intangible.

\section{Bibliografía}

BERG, Lorenzo (2003): Restauración iglesias de Chiloé, conservando lo infinito. Universidad de Chile, Universidad de los Lagos. Stgo. Editorial Universitaria. Chile. 2003

BERTRAND, Jean René (1999): “Geografía y peregrinaciones", en Coloquio Internacional Geografía de las Religiones. Santa Fe, Colombia.

BRAVO, Marcelo (2004): La Cultura chilota y su expresión territorial en el contexto de la globalización de la economía. Tesis para optar al Título de Geógrafo. Universidad de Chile, Facultad de Arquitectura y Urbanismo.

CÁRDENAS, R y Trujillo, C. (1987): Caguach, isla de la devoción. Religiosidad popular de Chiloé. Ediciones Literatura Americana Reunida. Santiago de Chile.

CÁRDENAS, R y Hall, C. (1989): Chiloé: Manual del pensamiento mágico y creencia popular. Editorial El Kultrun. Valdivia. Chile.

CÁRDENAS, Renato (2001): “Los pilares de la evangelización en Chiloé” (Documento). Archivo Bibliográfico y Documental de Chiloé, Castro.

CÁRDENAS, Renato (2005): "El dormitorio de los muertos". En Revista Patrimonio Cultural. $N^{\circ}$ 35. Año X. DIBAM. Santiago. Chile.

CASTELLS V., Margalida (2001): “Reencontrar el patrimonio. Estrategias de Desarrollo Territorial a partir de la Interpretación". Ponencia en Congreso Virtual Perspectivas del Turismo Cultural. www.naya.org.ar/turismo_cultural/congreso/ponencias/margalida_castells2.htm

CLAVAL, Paul (1995): La geografía cultural. Eudeba. Universidad de Buenos Aires.

GRENIER, Philippe (1984): Chiloë et les chilotes - Marginalité et dépendance en Patagonie Chilienne. Editorial EDISUD. Paris. Francia.

INE (2005): Chile: Ciudades, Pueblos, Aldeas y Caseríos. Instituto Nacional de Estadísticas. Santiago. Chile.

LEÓN, Marco Antonio (1999): La cultura de la muerte en Chiloé. RIL Editores. Santiago. Chile.

MILLAR, Walterio (2002): Historia de Chile. Editorial Zig Zag, Santiago.

MODIANO, Ignacio (1982): Precedentes teóricos y formales del tipo de iglesias de Chiloé. Universidad de Chile. Santiago. Chile.

MONTECINOS, Hernán (1995): Las iglesias misionales de Chiloé. Universidad de Chile, Facultad de Arquitectura y Urbanismo, Santiago. 1995. 
OBISPADO DE ANCUD (1982): Listado de las fiestas religiosas de Chiloé por parroquia y capilla, fechado 1982, inédito.

PLATH, Oreste (1993): L'Animita. Hagiografía folclórica. Editorial Nacimiento. Santiago de Chile.

PLATH, Oreste (1995): Geografía del mito y la leyenda chilena. Editorial Grijalbo. Santiago de Chile.

RETAMAL, Francisco (1983): El primer sínodo chileno de la época republicana: Ancud. Ediciones Universidad Católica de Chile. Santiago de Chile.

ROSENDAHL, Zeny (1996): Spaço \& Religión. Una abordagem geográfica. Universidad de Río de Janeiro.

URBINA BURGOS, Rodolfo (1990): Las misiones franciscanas de Chiloé a fines del siglo XVIII: 1771-1800. Editorial Elártole. Instituto de Historia, Universidad Católica de Valparaíso.

URBINA BURGOS, Rodolfo (1983): La periferia meridional indiana. Chiloé en el siglo XVIII. Ediciones Universitarias de Valparaíso. Universidad Católica de Valparaíso.

UNESCO (1972): Convención para la protección del patrimonio mundial cultural y natural. 17a. Conferencia General de la Organización de las Naciones Unidas para la Educación, la Ciencia y la Cultura. París del 17 de octubre al 21 de noviembre de 1972.

UNESCO (2003): Convención para la salvaguardia del patrimonio cultural inmaterial. 32a Conferencia General de la Organización de las Naciones Unidas para la Educación, la Ciencia y la Cultura. París 17 de Octubre 2003.

VÁSQUEZ DE ACUÑA, Isidoro (1956): Costumbres religiosas de Chiloé y su raigambre hispana. Centro de Estudios Antropológicos. Universidad de Chile. 1956. 